\title{
Rethinking nature journaling in the Kindergarten Program action research in learning and teaching
}

\author{
Hongliang $\mathrm{Hu}^{1}$
}

Accepted: 3 February 2022 / Published online: 4 March 2022

(c) The Author(s) under exclusive licence to Outdoor Education Australia 2022

\begin{abstract}
This qualitative action research study in a Canadian urban public elementary school proposes teachers and early childhood education integrate different types of nature journaling into the Kindergarten Program. In this study, analysis of data collected from weekly classroom lessons and student work samples through two action research cycles led to the identification of three types of nature journaling: 1) observation-focused nature journaling, which may encourage sensory engagement; 2) relationship-built nature journaling, which may help to foster a sense of connection with the natural environment; and 3) curriculum-connected nature journaling, which may contextualize nature journaling as an interdisciplinary pedagogical strategy. These three types of nature journaling are interrelated within the framework of ecological systems theory that guides this study. This study values whole child development and experiential learning. It emphasizes the pedagogical values and curriculum connections nature journaling can bring to the Kindergarten Program, especially when used as a way for students to explore environmental and nature education. Based on its findings, this study recommends that educators organize curriculum and foster students' interdependence in the context of real-world experiences through a nature journaling approach.
\end{abstract}

Keywords nature journaling · environmental education - Kindergarten children · interdependence $\cdot$ learning and teaching $\cdot$ nature connection

\section{Introduction}

Nature journaling is the maintaining of a personal or professional diary or journal to record observations, feelings, responses and reflections about the world of nature around us (Blum, 2018; Leslie \& Roth, 2000). It has been used by scientists,

Hongliang $\mathrm{Hu}$

hongliang.hu@tdsb.on.ca

1 TDSB Full-Day Kindergarten Program and OISE, University of Toronto \&TDSB EcoSchools Environmental Education Action Research Team, Toronto, Ontario, Canada 
naturalists, environmental professionals and outdoor educators (Johnson, 2014; Laws \& Lygren, 2020). In this study, educators put nature journaling into practice to integrate nature-based environmental education into a Canadian Kindergarten classroom in Toronto, Ontario. Using action research (AR), this study examines why educators may want to think about using nature journaling within their Kindergarten Program to support whole child development within the framework of ecological systems theory.

This qualitative investigation explores the impacts of nature journaling within a class of 28 Kindergarten students at a Canadian urban elementary school across two action research cycles: first within a face-to-face (F2F) classroom environment (preCOVID); then later within an online learning context (during COVID). Using examples from working with these students, this study aims to emphasize the pedagogical value of nature journaling through highlighting its inherent curriculum connections and potential for engaging in holistic, experiential teaching and learning in the Kindergarten Program. This research also uses examples to demonstrate how nature journaling techniques can be specifically modified to better suit young learners.

In sharing this research, this article will first situate this study within a literature review related to 1) the overall significance of nature journaling, 2) the connection between nature journaling and the ecological systems theory framework, and 3) the limited research on using nature journaling with young children. Next, it will detail the action research methodology, as well as the specific data collection methods used. It will describe the thematic analysis process performed on the data before presenting a discussion of its findings. Overall, this study found that integrating nature journaling in the Kindergarten Program may lead to the emergence of three main types of nature journaling, possibly each with a unique outcome: 1) observation-focused nature journaling, which may encourage sensory engagement; 2) relationship-building nature journaling, which may help to foster a sense of connection with the natural environment; and 3) curriculum-connected nature journaling, which may contextualize nature journaling as an interdisciplinary pedagogical strategy. This article will conclude with implications and future recommendations from this research.

\section{Nature journaling and its significance}

The significance of nature journaling has been documented in the literature. Laws and Lygren (2020) believe that educators can use journaling as an interdisciplinary approach to engage children with and in nature wherever they are. Nature journaling is considered an invaluable tool to uncover children's learning of nature through art, language, writing, science and inquiry and develop a growth mindset (Laws et al., 2010; Laws \& Lygren, 2020). Comparatively, Johnson (2014) proposes that nature journals of young children are important, acting as places to record what is seen and wondered; as learning platforms for developing ecological literacy that is age and developmentally appropriate; and as interactive spaces for developing relationships between children and the natural world through drawing and adult documentation. From a general to a comparative view of nature journaling discussed above, 
its significance is reflected in naturally reinforcing observation skills, obtaining real life experience within the natural world, providing documentation of learning, and enhancing children's learning in various ways.

White (2004) found that cultivating young children's relationships with nature benefits their development while Sobel (1996) believed that developing children's empathy with the natural world should be the main learning objective for children ages four through seven. Through relationships with nature, children can develop environmental values needed to become the future stewards of the Earth who will preserve the diversity and wonder of nature (White, 2004). Nature journaling can be one way for children to record their natural curiosity, helping them cultivate the joys found in contact with nature and develop their awareness and appreciation of the earth. Overall, in this study nature journaling was a way for children to record their direct encounters sensorially, cognitively and affectively with natural environments, guided by ecological systems theory.

\section{Theoretical framework: ecological systems theory}

The ecological systems theory first developed by Urie Bronfenbrenner (1979) examined a child's development within the context of the multifaceted system of diverse relationships. As a theory of human development, everything is seen as interrelated and our knowledge of development is bounded by context, culture, and history (Bronfenbrenner, 1979; Darling, 2007). Bronfenbrenner (1979) further depicted context, culture, and history as concentric nested circles comprising the microsystem (the child's immediate settings), mesosystem (about interactions and interrelationships between the microsystems), exosystem (social structures or settings), and macrosystem (the broader level policies, political institutions, and cultural beliefs) and subsequently added the chronosystem to denote dynamic system changes over the human life. His ecological model was framed within the human-centered sociopolitical-environmental context of its time. Therefore, Bronfenbrenner's theory has influenced early years practitioners to look at those different types of environmental systems that impact indirectly on the lives of children. It offers a means of thinking about how wider and unseen aspects of society may impact their development and learning through ecological systems and the relationship between each child's unique biology and the environments in which they grow up (Darling, 2007; GuyEvans, 2020).

At its core, environmental learning is about understanding the interconnections that exist in nature and between nature and human societies. Elliott and Davis (2018) proposed rethinking Bronfenbrenner's ecological theory to de-center the human condition and strengthen children and nature connections that have implications for early childhood education philosophy and pedagogy. This ecological worldview implies that children are connected with the natural world, so that they should become agents of taking care of environment. As children grow, they should be better able to possess a greater understanding of the characteristics of themselves, others, and complex ecological systems and their mutual influence on the environment. Bronfenbrenner's (1979) ecological systems theory emphasizes seeing a child's 
learning and development as multifaceted and affected by many interacting factors, and recognizes various phenomena as interconnected components that interact with one another to make a dynamic whole. Built upon Bronfenbrenner's theory, Elliott and Davis value the interrelationship and interconnection between children and the natural world, and develop children's beliefs, attitudes and values, and help them care for and feel connected to nature through a developmental, ecological lens. Hence, the dynamics and reciprocity of interrelationships between humans and nature must be recognized in any theorizing about human development (Elliott \& Davis, 2018).

\section{Nature journaling with young children}

Research shows that nature journaling is a tool for children's learning through drawing, writing, science and art to develop observational skills, deepen nature exploration, increase knowledge of their local environment and grow a deeper relationship with nature (Cormell \& Ivey, 2012; Laws et al., 2010; Johnson, 2013, 2014; Spinazola, 2015). Johnson (2014) believes that children 4 and 6 years old can draw symbols, write words, even sentences on the nature journal. Nature journaling for younger children is a journaling experience more enjoyable and spontaneous, a wonderful tool of expression of their uniqueness and creativity. Nature journaling focuses more on learning observation skills instead of drawing a perfect picture. Drawing and writing in nature journals connects children to nature and their immediate environments, embeds interdisciplinary learning, and encourages various styles of learning through cross-curricular connections. (Laws et al., 2010; Laws \& Lygren, 2020; Lygren, 2016; Leslie, 2001, 2002; Cormell \& Ivey, 2012). In addition, sensory observations along with writing will deepen children's connection and awareness of their own bodies and sensitivity to their surroundings, cultivate deeper sense of curiosity, then inspire children to follow their own trails of questions towards natural discoveries (Laws et al., 2010).

There is limited research of nature journaling related to young children, however, a couple of research studies, such as both Laws' and Johnson's research, address that nature journaling, as a form of experiential learning, allows children to experience nature outdoors authentically, exposed to the elements and exploring nature with their senses, and putting those senses to paper with creativity (Laws et al., 2010; Johnson, 2013, 2014). Johnson (2014) emphasizes that nature journaling is just as important as teaching reading and math when helping young children get engaged with the elements of nature. Nature journals spark young children's interests in oral and written language and improve both literacy and ecological literacy development during the early childhood sensitive period for language development (Johnson, 2014). One of the purposes of nature journaling is providing opportunities to study the natural world, growing a deeper relationship with the Earth, and caring for the Earth (Laws et al., 2010; Laws \& Lygren, 2020; Lygren, 2016). Johnson (2014) strongly recommends the practice of nature journaling in the early childhood outdoor classroom environment to foster naturalist intelligence and academic enthusiasm. Based on the above literature review, a research gap has been identified, as 
there do not seem to have any action research studies related to nature journaling in Kindergarten Programs. Nor has this research topic been addressed in conjunction with the interdependence of sustainability and enduring understanding of how we are all connected and interrelated in human systems and natural systems.

\section{Integrating nature journaling into weekly activities}

\section{Research context and the AR cycles}

I am an early childhood educator (ECE) at a Canadian urban elementary school. I am also a researcher belonging to the Environmental Education Action Research Team, which is run in partnership through the Ontario Institute for Studies in Education (OISE, University of Toronto) \& the Toronto District School Board (TDSB)'s EcoSchools program. This action research (AR) study was conducted in my Kindergarten classroom with my 28 students during the 2019-2020 academic school year. This study implemented the cycle of classroom action research (CAR) found in Fig 1 (Muhsin, 2017). The process of data collection was divided into two AR cycles with each cycle consisted of four phases: Planning, Action, Observation and Reflection. The first AR cycle occurred within face-to-face (F2F) learning at my school and lasted 10 weeks before the Ontario Ministry of Education announced that publicly-funded schools would close for in-person learning on March 20, 2020 due to the COVID-19 pandemic. The second AR cycle occurred within online learning after my school shifted to remote education in April 2020 and continued for another 10 weeks.

During the first AR cycle of F2F learning, I used the existing schoolyard as the base of weekly nature journaling, and applied a project-based learning approach in Environmental Education in the Kindergarten Program in order to evoke children's interests. The project-based learning approach in Environmental Education

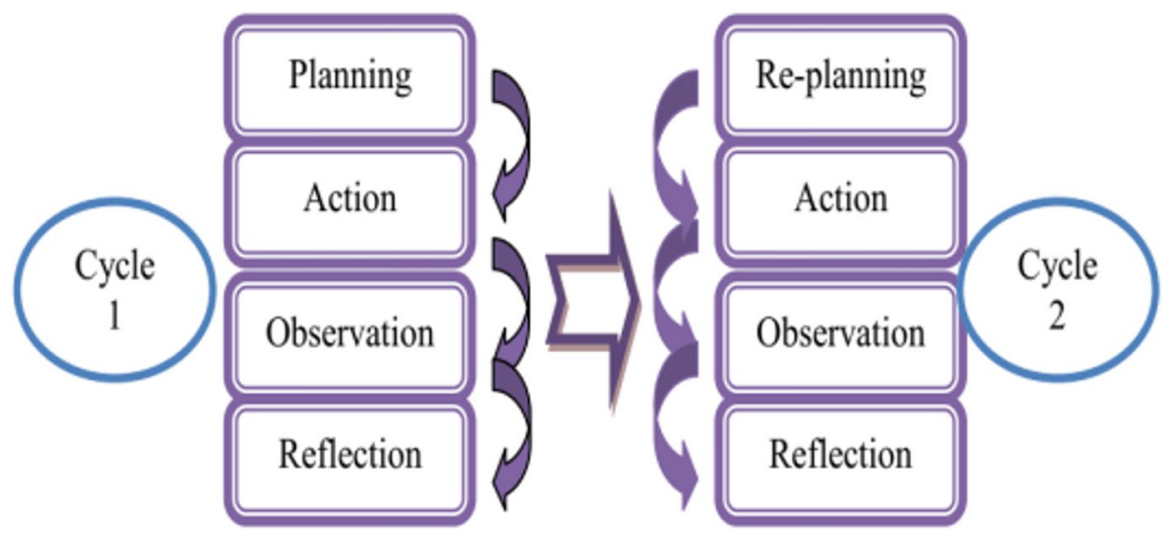

Fig. 1 The Cycle of Classroom Action Research. Note. This figure is adopted through the Scheme of AR Phases created by Muhsin (2017) 
empowers children's learning as active participants and involves their in-depth investigation of an environmental learning topic (Alfonso, 2016; Abshor, 2017). During the second AR cycle, the context of this action research changed from a F2F classroom to an online classroom. I carried on the project-based environmental learning but shifted the learning perspectives from school to home. In the process of online data collection, I re-planned to meet children's needs through our online classroom, rebuilt relationships through family engagement and reconnected nature with Kindergarten children through weekly nature journaling. The role of learning at home with parental involvement, engagement and partnership enriches children's experiences and development of positive attitudes towards and expectations for education (O'Toole et al., 2019). The nature journaling entries got all collected except those who were absent during the two AR cycles.

\section{Research methods and ethical considerations}

Three methods were used in this study as data was collected from: 1) weekly nature journaling lesson plans (see examples in Table 1); 2) student work samples; and 3) weekly and monthly reflective journals. Weekly nature journaling lesson plans convey the purpose and objectives of environmental learning (which

Table 1 Examples of Weekly Nature Journaling

\begin{tabular}{|c|c|}
\hline Nature Journaling & General Guidelines \\
\hline 'Sit Spot" & $\begin{array}{l}\text {-Sit quietly in a spot to document what is observed } \\
\text {-Open senses to cultivate naturalist skills, record experiences in connec- } \\
\text { tion with nature }\end{array}$ \\
\hline Scavenger Hunt & $\begin{array}{l}\text {-Explore natural environments through a nature walk } \\
\text {-Search for natural items through five senses and record them }\end{array}$ \\
\hline Winter Tree Inquiry & $\begin{array}{l}\text {-Draw, paint or write about winter tree's investigation } \\
\text {-Discuss winter trees with no leaves or green leaves }\end{array}$ \\
\hline Sunset Nature Journal & $\begin{array}{l}\text {-Observe sunset and draw, paint, write or record it creatively } \\
\text {-Questions to engage children's learning (e.g., What do you observe while } \\
\text { watching sunset? How does watching sunset make you feel? Why does } \\
\text { the sunset rise and set?) }\end{array}$ \\
\hline Water Ecosystem & $\begin{array}{l}\text {-Investigate water around home and in nature } \\
\text {-Record who/what/why water is needed everywhere } \\
\text {-Discuss the relationship of water, all living things, and the Earth }\end{array}$ \\
\hline Mangrove Tree Ecosystem & $\begin{array}{l}\text {-Take a virtual field trip to Anne Kolb Nature Center } \\
\text { - Ride a boat through the mangroves, and record what is observed }\end{array}$ \\
\hline Elements of Medicine Wheel & $\begin{array}{l}\text {-Integrate Indigenous Medicine Wheel into nature journaling } \\
\text {-Observe nature and document four elements of medicine wheel }\end{array}$ \\
\hline Regrow Vegetable in Water & $\begin{array}{l}\text { - What vegetables will regrow using a scrap of the original food? } \\
\text { - Investigate which factors are important for vegetables to regrow }\end{array}$ \\
\hline Adopt-A-Tree & $\begin{array}{l}\text {-Invite children to choose a particular tree to observe. } \\
\text {-Document the date, time, weather, the name of the tree, how big this tree } \\
\text { and why this particular tree is adopted }\end{array}$ \\
\hline
\end{tabular}

Note. A list of some examples of nature journaling lesson plans, including general guidelines 
is connected to my students' interests) as well as the instructions students were provided in creating their nature journals. Student work samples document students' learning by recording what is learned, speaking to students' actions and thoughts in an authentic way. The student work samples that were included for analysis were samples that connected to the research topic and can answer the research questions. Reflective journals constitute a source of narrative research and comprise an important part of documenting my practice.

Techniques for journaling with young children need to be considered in research. Researchers need to critically reflect on the research methods and approaches that they use with young children, and the most appropriate way in which to apply them, in order to, as far as possible, maximize their benefits (Fargas Malet et al., 2010). Children's rights are a part of the ethicality of the research that can be justified with the interaction between the researcher and research participant. Children were asked to give assent for their participation in research, where research participants are children as vulnerable and relatively powerless, it is important to ensure that they have opportunities to make their decisions in research. Before starting the research, it was necessary to have the Principal's consent and their parents' permission as well, which was provided through informed consent forms that ensured respect for anonymity, confidentiality, and privacy.

The Ontario Ministry of Education (2016a, b) describes that educators coconstruct children's learning through play and inquiry in the Ontario's two-year Full-Day Kindergarten Program. From a social constructivist perspective, as educators assess children's learning, assessment shifts from the product of children's learning to an emphasis on assessing the process of children's learning (Dahlberg et al., 2013; Chiarotto, 2011). Keel (2018) proposes that educators as environmental facilitators act as a connection between education and society as a whole to provide children the opportunities for environmental learning. Utilizing nature journals can empower children to explore their place and environment in their world, and increase their awareness of nature (Keel, 2018). When beginning to integrate nature journaling into early childhood environments, Johnson (2014) believes the role of educators as engaging children in aspects of the natural world and as sparking their wonder through their prior knowledge and memories. As a result, journaling offer educators an academic foundation for increasing outdoor learning time and improving children's experiential learning experiences in, with and about nature.

Taken from the perspective of the Ontario Ministry of Education in the Kindergarten curriculum, of a social constructivist, and of environmental education, the roles of educators can be seen in three new ways through integrating nature journaling into the Kindergarten Program:

1. Educators as co-explorers through navigating and observing the natural world.

As co-explorers, educators support to guide, nurture, hypothesize, and solve problems side-by-side with children, and document what they explore and wonder 
through nature journaling. As children observe the natural world, educators provide them with prompts for further investigation to foster inquiry and deepen their connection with nature.

2. Educators as co-learners through co-constructing learning about nature journaling.

Educators are considered co-learners by planning nature journaling activities based on the child's interests, asking questions to further understanding, and actively engaging in the activities alongside the child. As children learn in and about nature, educators construct knowledge together with children through observation and reflection.

3. Educators as co-thinkers through exploring the interrelationship between nature and environment.

Educators are considered co-thinkers with a natural love and passion for increased knowledge in thinking methods, to integrate curriculum and nature journaling together. As children interact with nature, educators scaffold learning by providing resources and remind children of the connections and relationships between all living things.

\section{Data analysis}

Thematic analysis was used to analyze the qualitative data drawn from weekly nature journaling lesson plans, student work samples and weekly and monthly reflective teaching journals. This study used a four-step process of thematic analysis. The first step of thematic analysis was gathering and reviewing all of the data. Student work samples were gathered, and lesson plan and my own reflective journals were organized for review and analysis. The second step was creating initial coding categories. Through identifying words, phrases or passages in the texts, or patterns in the photographs or images of student work samples, lesson plan and reflective journal, relationships were found and identified as initial codes. Triangulation of the three forms of data used in this study (student work samples, lesson plans and reflective journals), developed a comprehensive understanding of the types of nature journaling in learning and teaching in the Kindergarten Program. These initial codes provided a way to gain an overall understanding of the data as well as the patterns emerging within the data.

The third step of thematic analysis was reviewing those initial codes, revising and combining them into themes. After coding all of the data, similar types of data were collated together and patterns were identified among them that led to an understanding of broader themes. In the process of the data analysis, reviewing the weekly nature journaling lesson plans, analyzing student work, and reflecting regularly have been an essential part of teaching and learning in the process of AR. Through the reflective process, examining samples of students' nature journaling helped to 
understand our own work, and helped us to develop a new and deeper understanding of our students. Through closely analyzing the data, three major themes emerged, which are detailed in the following section.

\section{Findings and discussion}

The data revealed the three themes of using nature journaling in learning and teaching with Kindergarten students: 1) observation-focused nature journaling, which may encourage sensory engagement; 2) relationship-building nature journaling, which may help to foster a sense of connection with the natural environment; and 3) curriculum-connected nature journaling, which may contextualize nature journaling as an interdisciplinary pedagogical strategy.

\section{Theme 1: Observation-focused nature journaling}

Kindergarten children's nature journaling is about observing nature that surrounds them in their immediate environment and experiencing nature through sensory engagement. Through observation, children gather information in nature, about nature and from nature, and share their perceptions, feelings, wonder and inquiry in their journals. One example was a 'sit spot' nature journal that recorded what was observed silently as indicated in Fig. 2. Students found their own place in an outdoor area, then paid attention to whatever inspired them and recorded their experiences in their journal. Sit Spot journaling was an opportunity for students to focus not just on observing their surroundings but also on awakening their senses and cultivating awareness in the present moment. Children record how many different colors are in each spot, and how many different textures they can feel. They look above, below, and behind themselves and comment on what they see. They sit quietly and listen for many sounds they can, such as birds, squirrels, and wind rustling the leaves, people talking and cars moving. Thus, in nature journaling, including sit spots can sharpen

Fig. 2 Example of a 'Sit Spot' Nature Journal. Note. This figure shows a student spending time in silent observation and involved in sensory engagement, drawing and writing what was observed in nature

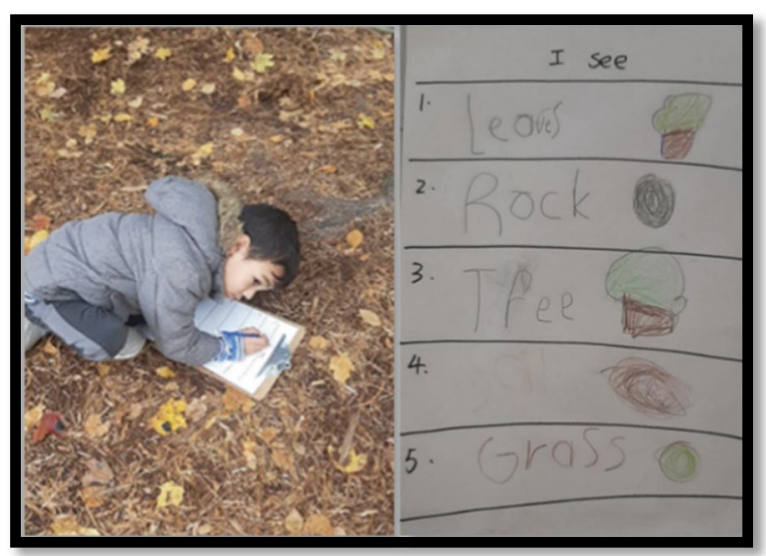


children's competence in observation through sensory engagement. The journaling outing may be an opportunity to hone observation skills, take the nature journal to grow, fit within a wider learning experience and connect to other topics as a critical part of the learning process.

In comparison with silent observation in a 'sit spot' nature journal, another example was a scavenger hunt nature journal recorded through their senses as indicated in Fig. 3. In a nature scavenger hunt, students experienced walking outdoors to explore natural environments, searched for natural items and documented what was observed in their nature hunt. Here sensory engagement can be a state of being genuinely involved and interested in nature with a child's five senses. Children may learn best when they are deeply engaged in what they are experiencing with nature. The natural outdoor environment provides for direct contact with natural features of the environment through guided experiences and observations utilizing all of the senses. A child's nature journal forges the connection between themselves and the pulses of life they sense and observe in nature. A child's natural curiosity plays a big part in nature journaling through sensory engagement - it leads them to explore with their bodies, minds and senses, and inspires them to ask questions, test theories, solve problems, think creatively, and make meaning of the world around them.

The importance of nature journaling aligns with the position of Johnson (2014) about the young child's nature journal as a place for developing spontaneous observation and facilitating nature connection closer to them. During the nature journaling time, spontaneous observation supports children's autonomy, having their own ideas with adult-led guidance, making links with nature and choosing ways to do things. As children further develop observational skills in their nature journaling (see examples of sunset nature journal in Fig. 4), they learn about the interrelationship between themselves, nature and environment. This observational perspective of nature journaling implies a way for children to explore nature through observation, to get engaged and interpret observation from their lived experiences in nature

Fig. 3 Example of Scavenger Hunt Nature Journal. Note. This figure demonstrates exploring and discovering the outdoors through senses and observations and recording what was observed in nature

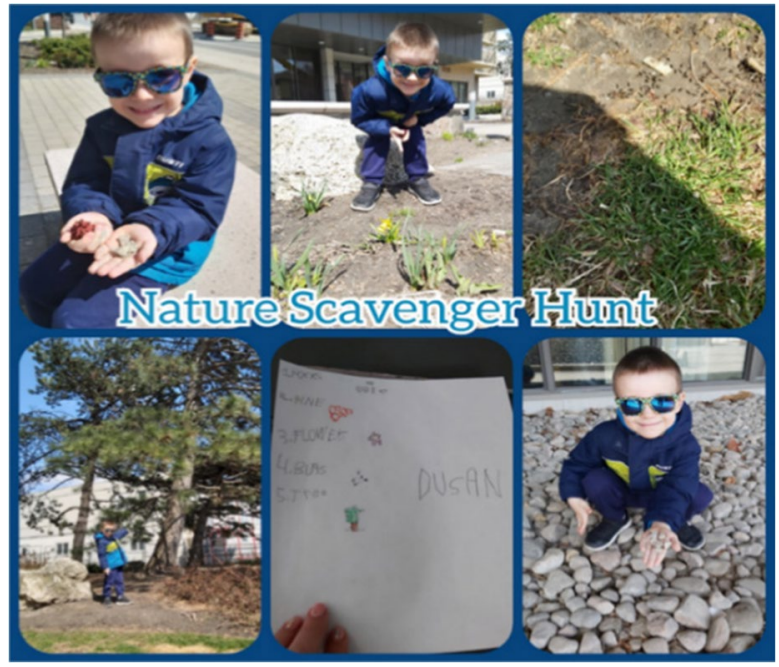



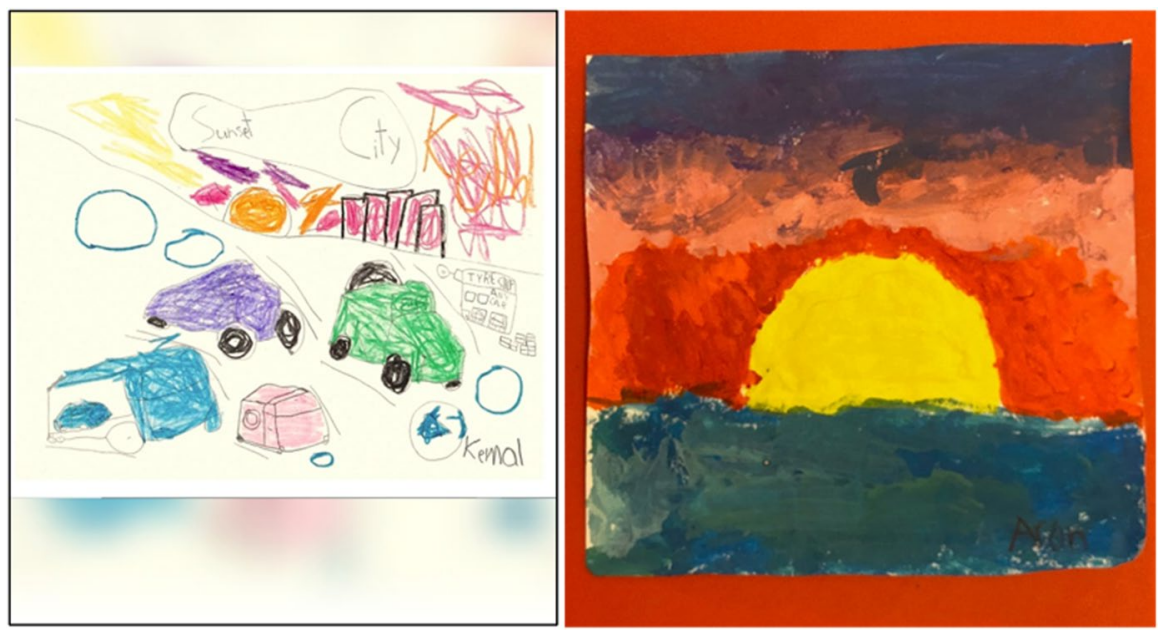

Fig. 4 Examples of Sunset Nature Journal. Note. This figure shows students' obeservation of sunset from a prefereable place and documents a sunset city by drawing and writing, and a colourful sunset in nature by an oil pastel art

(Leslie \& Roth, 2000), and is a place for children to record the natural insights and wonder as developmentally appropriate (Johnson, 2014). Moreover, it is a flexible and hands-on teaching tool (Leslie, 2002) for educators to teach a focus of observational skills in nature instead of drawing skills on the paper (Leslie, 2001). While the heart of nature journaling is not developing drawing skills, the very act of drawing something encourages children as the observer to forge meaningful connections. The ultimate purpose of nature journaling is not the case product-oriented drawing work as Leslie and Roth (2000) believe that it is likely to find patterns in nature and learn about the principles governing the natural world, and develop a broad understanding of nature and environment in the ecosystem.

Kindergarten children's nature journaling represents the age of nature exploration with the senses to promote the whole child development in nature. To put it simply, it is about exploring nature with their senses and using their senses to regain that sense of wonder in, about and with nature. The sensorial aspect of nature journaling for young children is reflected in the value of Johnson's research (Johnson, 2014) that highlights nature journaling and its techniques as in early childhood should be modified for the young child to incorporate a sensorial-based journaling practice into their environments. By recording all of the interesting things they see, smell, hear, feel and wonder about, children can gently develop the lifelong habit of nature observation. To go deeper, the nature journaling of kindergarten children is opening their senses, their hands, their heart, and their mind to discover nature secrets. In line with the whole child development and a foundation of environmental literacy highlighted in NAAEE $(2000,2019)$, it is vital for educators to see the whole child in order to reduce restrictions on their participation in nature journaling outdoors and promote ways of valuing and including all children in nature. 
Within the whole-child approach, educators shift their perspectives from a focus on narrowly defined academic achievement to one that incorporates a broader view of the skills and knowledge that all children must develop in environmental education. This whole-child perspective of nature journaling resonates with the developmentally appropriate environmental education program planned with the whole child in mind highlighted in the document of The Early Childhood Environmental Education Programs: Guidelines for Excellence (NAAEE, 2000). With the whole child in mind, educators develop the whole-child approach for teaching nature journaling and acknowledge that we are all interconnected and interdependent on natural systems. It completely changes how we see the world and how we see ourselves in it. The natural world becomes a dynamic, constantly evolving system that we are a part of.

In essence, nature journaling of Kindergarten children is an art of observing nature through sensory awareness. As learning tools connected with developmentally and age-appropriate practice with young children, nature journals are flexible in making observations and recording what they see, hear, feel and smell. This method of hands-on learning can be a powerful experience for Kindergarten children because it helps the observers slow down, carefully take note of their surroundings, make first-hand, concrete observations of nature, document their feeling, assimilate the information in nature and reveal the big picture patterns of an environment.

\section{Theme 2: Relationship-built nature journaling}

Nature journaling of Kindergarten children serves as a bridge to find self, support the whole child and build relationships with others, families, nature, the local environment, the natural world and our Earth. This relationship starts from connecting self with nature to extending an interconnection with all living things and non-living things on our Earth. Nature journals in trees, journals in drawing plants, animals, flowers, butterflies, birds, sunset, rocks, leaves and many more are exposed to the outdoor setting. An example of a nature journal in the mangrove tree ecosystem in Fig. 5 illustrates that the mangroves provide the mangrove tree crab to live on the tree it uses for a food source and a shelter from predators. Another example of a nature journal in the water ecosystem in Fig. 6 speaks of the interrelationship among water, tree, butterfly, bee, plant, flower, and our Earth. Correspondingly, nature journals of the mangrove tree and water nature journals speak to exosystemic relationships. When a child is immersed in observing the surrounding environment and recording what its surrounding environment look like, this nature journaling develops a connection with self, others and the immediate environment.

Nature journaling could potentially promote children's relationships at all levels. At the micro-level, nature journaling is an exploratory way for children to interact with individuals, peers, small groups, families around them and nearby nature. A nature journal becomes an opportunity for personal growth, family engagement and school-based learning to study the evolving natural world. Some entry examples connect to the microsystem and mesosystem, such as the entry on regrowing vegetables and investigating water at home (see Fig. 9); the entry on winter tree inquiry 
Fig. 5 Nature Journals in the Mangrove Ecosystem. Note. This figure demonstrates the relationship between Mangrove tree and tree crab and how the tree crab and the mangrove tree rely on each other

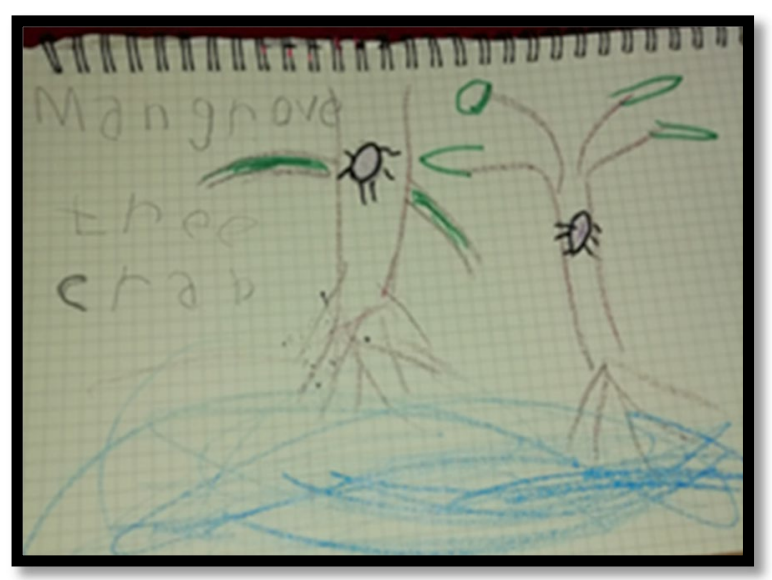

Fig. 6 Nature Journals in the Water Ecosystem. Note. This figure demonstrates the interrelationship among water, tree, butterfly, bee, plant, flower, and our Earth. All are interconnected

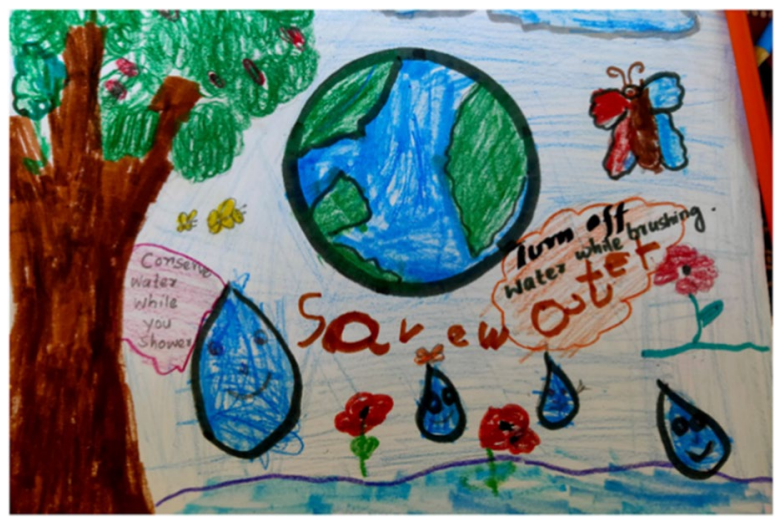

at the schoolyard indicated in Fig. 7; the entry on sunset at a preferable place (see Fig. 4), such as from the home window, the backyard, or near the local lake. The immediate relationships in a microsystem and mesosystem are built through mutual influence, reciprocal communication and direct interaction of siblings, parents, school peers and educators in the process of nature journaling. The micro-level relationship of nature journaling resonates with the microsystem and the mesosystem that encompass the relationships and interactions a child has with one's immediate surroundings in Bronfenbrenner's Ecological Systems Theory (Bronfenbrenner, 1979; Guy-Evans, 2020). A child's relationship with the natural environment in one's individual microsystem and mesosystem is not built upon independently, but is interconnected and they assert influence upon one another.

At the macro-level, nature journaling is a creative way for children to rediscover nature and shape the local environment, the natural world and the Earth and be shaped as well. Some nature journal examples likely connect to the exosystem and macrosystem, such as the entry on visiting the local park (see Fig. 8), taking a virtual field trip to nature center Anne Kolb Nature Center (see Fig. 5); investigating the 

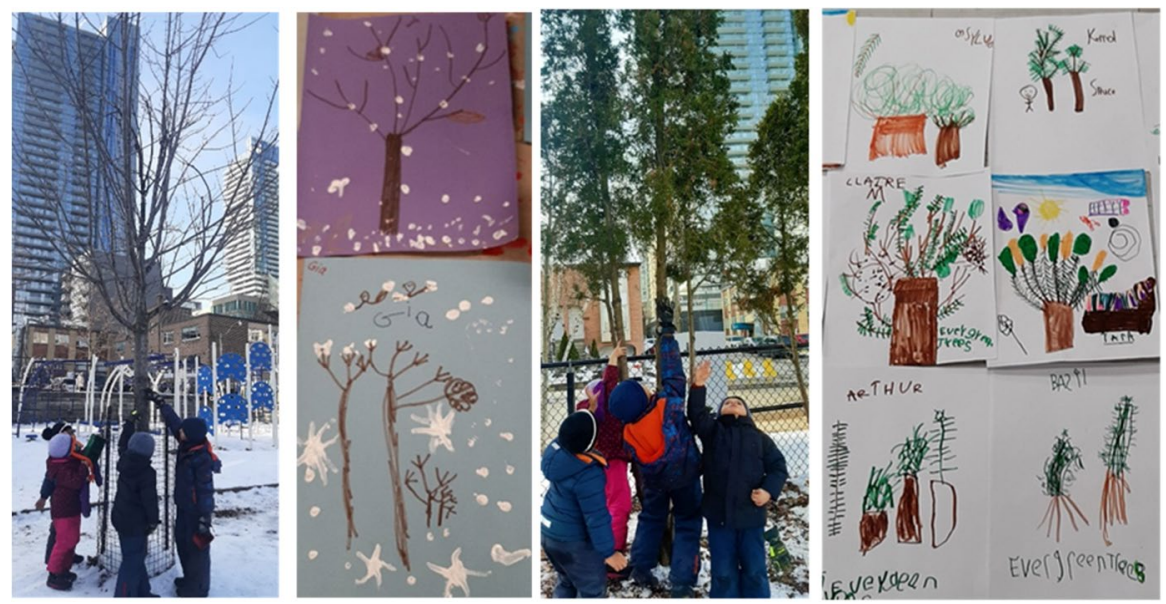

Fig. 7 Examples of Winter Tree Inquiry Nature Journal. Note. This figure shows the entry into exploration and inquiry on winter trees with no leaves and with green leaves at the schoolyard. The process of inquiry supports students to connect with one another and influence how they form relationships with people, places, ideas and environment through nature journaling

Fig. 8 Example of Adopting a Tree Nature Journal. Note. This figure demonstrates engaging students in real-world applications in the local environment over time in connection with the Ontario Kindergarten curriculum

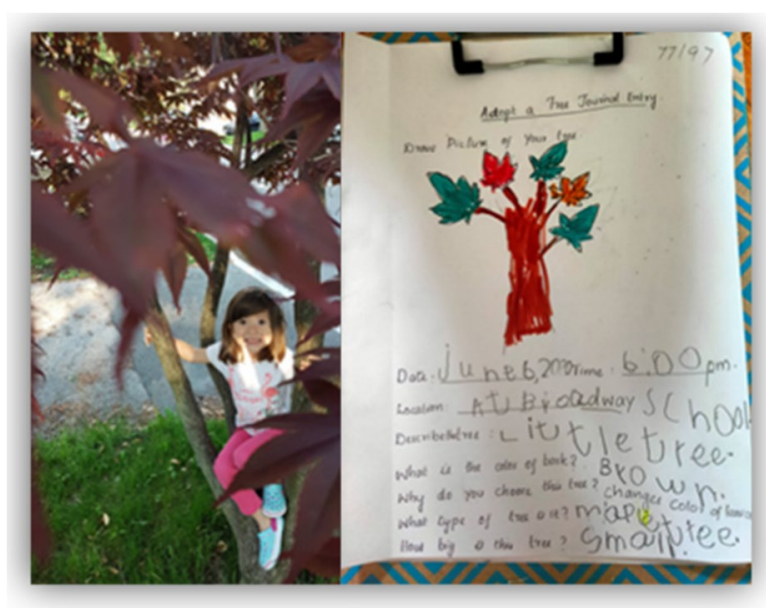

water in the neighborhood (see Fig. 6) and integrating Indigenous culture into nature journaling (see Fig. 10). In the exosystem and macrosystem, relationships are built through external environments and real-life experiences. In the process of nature journaling, the external relationships influence a child's learning and development indirectly through culture, community, and society. Within the chronosystem, the data in this study has not shown much evidence on children's experience and their environments in a person's life span. The macro-level relationship of nature journaling is tied with the exosystem and the macrosystem in which children do not function directly as the outermost layer in the child's environment, and which encompass 


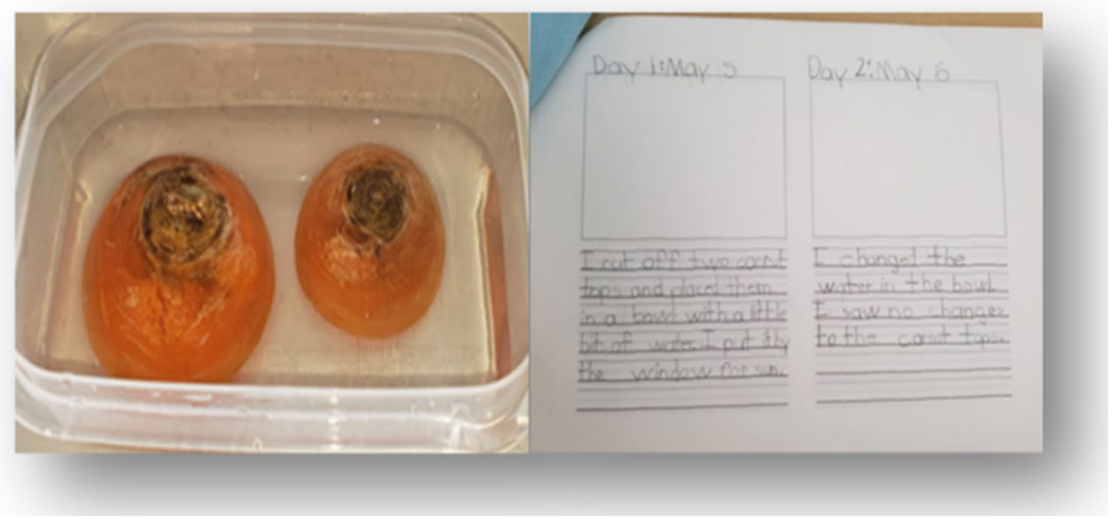

Fig. 9 Example of Regrowing Vegetables in Water Nature Journal. Note. This figure shows designing science experiments to investigate which factors are important for vegetables to regrow and document their nature regrowth journal

Fig. 10 Example of Four Elements of the Medicine Wheel in Nature Journaling. Note. This figure shows interconnection with nature as wholeness and completeness associated with the Kindergarten curriculum within an Indigenous perspective

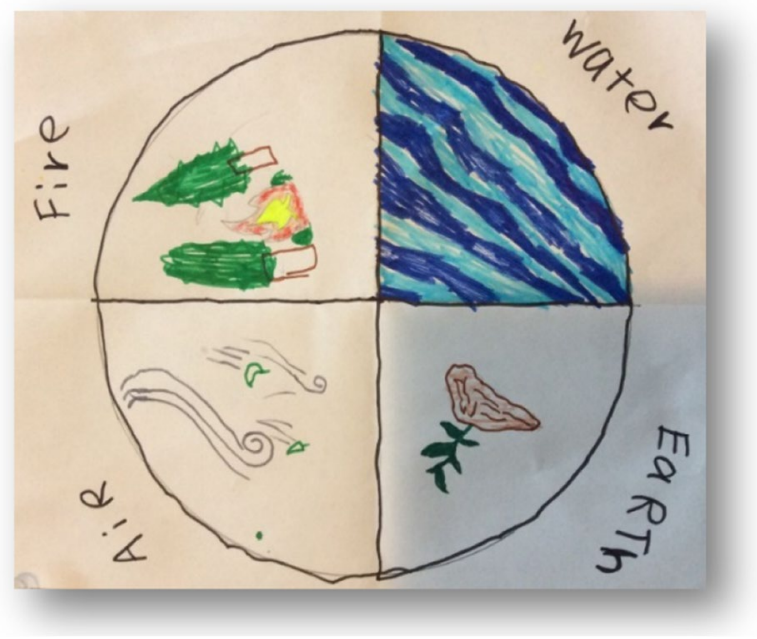

the dimension of time as it relates to a child's environments (Bronfenbrenner, 1979; Guy-Evans, 2020). Children are constructing understandings and building relationships to the natural world in their outmost layer systems and their experiential experiences can shape and augment their conception of relatedness to the natural world.

The intersectionality of micro-level and macro-level relationships of nature journaling between environmental education and children's development is reflected in the critical point of Bronfenbrenner's Ecological Systems Theory (Bronfenbrenner, 1979; Guy-Evans, 2020). Environmental education programs have traditionally concentrated on the ecosystemic and ekistic relationships and Bronfenbrenner's Ecological Systems Theory looks at a child's development within the context of the system 
of relationships that form his or her environment. On the one hand, to rethink nature journaling in learning and teaching, educators look not only at the child and her immediate environment, but also at the interaction of the larger environment as well. On the other hand, educators consider how children and we are part of that ecosystem and that diversity. Through an ecological exploration of the interdependence of all living things, children learn to connect with nature, appreciate, respect, honor nature and all that it encompasses, and grow a deeper relationship with the natural world, to develop a greater awareness and caring for the Earth.

In summary, nature journaling of Kindergarten children is indicative of relationship building with natural environments and is a potential way to creatively connect and build their personal relationship with the natural world. It is this relationship that will carry meaning into their understanding of nature. Through the process of nature journaling, Kindergarten children capture their discoveries on paper and reflect more deeply on the experience of being in connection with nature and the Earth. As reflecting on their meaningful experience, children build deeper and longer lasting memories of the natural world, appreciate nature, and uncover new ecological perspectives.

\section{Theme 3: Curriculum-connected nature journaling}

Nature journaling of Kindergarten children serves as an interdisciplinary tool to connect with the curriculum and may prove to be an effective way for cross-curricular teaching and learning to educate the whole child. The frames in the Ontario Kindergarten curriculum (Ontario Ministry of Education, 2016a) are intertwined with weekly nature journaling integrated in the Kindergarten Program. The Kindergarten frames grow out of the foundations for learning to support an approach that aligns with the way children's learning naturally occurs and that focuses on aspects of learning that are critical to young children's development. The frames reflect the integrated way in which learning occurs during children's play and inquiry in Kindergarten (Ontario Ministry of Education, 2016b, p. 13-15).

Curriculum-connected nature journaling is further reflected in the recommendation of Laws and Lygren (2020) that educators can leap into journaling with students with curriculum plans, advice and field experiences in nature. Nature journaling is a powerful adjunct to teaching science and should be a standard part of every classroom (Laws et al., 2012). A journal entry of adopting a tree in Fig. 8 demonstrates developing early literacy, numeracy, and art in connection with the Ontario Kindergarten curriculum. Recording the date, location, and weather helps focus children on the big-picture context of that journal entry. The journals can become a place for creative writing, scientific observations and personal reflections. A nature growth journal in regrowing the vegetables in water in Fig. 9 is one of the typical examples of teaching science as an interdisciplinary approach. This figure demonstrates how children record gardening in connection with observation, investigation, writing, science and reflection in the process of nature journaling. Students learn how to regrow vegetables from scraps and further investigate some of the most common vegetables that regrow: not only carrots but also celery; lettuce; and other vegetables through the nature regrowth journaling. This 
nature journaling supports students' drawing and writing in response to observations of nature growth day by day.

Nature journaling with Kindergarten children has the potential to capture that richness and Indigenous perspectives on connecting and interweaving the threads of curriculum and learning. The Indigenous culture has an orientation to learning that is metaphorically represented in its art forms, its way of community, and its way of understanding itself in relationship to its natural environment. An Indigenous lens offers a cross-cultural encounter supporting children's natural curiosity and exploring their learning about nature and environmental inquiry (Anderson et al., 2017). Fig. 10 is one of nature journal artwork examples of four elements of Medicine Wheel within Indigenous perspectives on understanding self and itself in relationships to its natural environment. Within the circle of the Medicine Wheel can be found the four elements of Air, Water, Earth and Fire. As students explore each of these elements of nature, they expand their circle beyond the classroom to the natural world outside and there is the understanding everything are all connected. Precisely, these nature journals show cross-curricular connections with language, math, writing, science and arts. "Journaling, as part of a school curriculum, strengthens and refines students' cognitive skills by teaching them to observe, to become aware of what they have observed with all of their senses, and, to exercise their imaginations and critical skills through developing hypotheses to explain what has been observed" (Laws et al., 2012, p. 4).

For a further discussion, this interdisciplinary combination of art, science, writing, and observation exemplifies the action research's goals in creating educational programs: to engage Kindergarten students in the incredible natural world around them, to inspire them to keen observations of the wild places in the schoolyard, in their own backyards and in their local park, and to foster in them a desire to love, appreciate and protect nature and environment. Nature journaling is a valuable, multidimensional approach to language, writing, science and art. Through nature journaling, students may build neural pathways that enable different brain regions to communicate with each other, and might result in more flexible thinking and creative problem-solving in all areas of life. This approach to nature journaling also offers students an excellent way to learn and practice a growth mindset through nature and science.

In short, nature journaling of Kindergarten children is curriculum connected as an interdisciplinary pedagogy. It can incorporate such diverse subjects as science, language arts, visual arts, and even math into children's learning indoors and outdoors. By developing a nature journaling practice, educators can seamlessly weave in a variety of topics to encourage and deepen cross-curricular connections. This interdisciplinary pedagogy engages children in the natural world, and inspires them to become keen observers in nature, and fosters in them a desire to take care of natural environments.

\section{Considering the themes as a whole}

Taken together, the three types of nature journaling in learning and teaching with Kindergarten children are interrelated through observation, sensory engagement, and a connection with a natural environment and curriculum. Children's learning and development occur in the framework of ecological system theory and nature 
journaling really matters with a focus on those values and pedagogies for Kindergarten-aged children that link interdependence. Within the perspectives of interdependence, children observe nature and environment through multiple senses, develop and maintain relationships with the natural world through experiential learning, promote critical thinking through nature journaling as explorers, learners and thinkers and understand how living and non-living things depend on one another in the ecosystem. As children observe nature and environment carefully and sensitively, educators see them learning. When educators approach observation of children with an open mind, we can observe the richness of their play and interaction through a nature journaling environmental pedagogy. On the one hand, we can become aware of what children know and can do, and use this information to ensure that what we provide a nature journaling curriculum is closely linked to their abilities and needs. On the other hand, the three types of nature journaling in learning and teaching with Kindergarten children enhance our knowledge and understanding of how children develop and learn. This dynamic approach to nature journaling in learning and teaching enables us to go beyond the idea of normative developmental expectations and outcomes measures and enables us to really see, and celebrate, children as individuals.

\section{Conclusion}

This study explores nature journaling as a pedagogical tool for environmental and nature education. It shows that there is potential for children to learn more about human-nature interconnectedness through the process of weekly nature journal entries over a long period of time. It also shows that aspects of microsystem, mesosystem, exosystem, and macrosystem were captured in these students' journal entries except that the chronosystem needs to consider nature journaling over the life course of children in research. Through the integration of three major types of nature journaling, educators and practitioners can offer young children more opportunities to develop an understanding of the dependence between humans and the environment where they live. Educators and practitioners can also cultivate children's naturalist skills, realize the potency of the nature journal as a tool for environmental and nature education, and discover that the learning process is more important than the end product. Most importantly, nature journaling provides an open means for children to make a connection to their natural world and understand the environmental interdependence that shows the relationships between all living things, including humans and different types of environmental systems within the ecological worldview.

The implications in this study involve Kindergarten curriculum and pedagogy. Nature journaling provides an outlet for educators to rethink prescribed curriculum that dictates what and when topics are taught. Linking journaling to the classroom also allows children to make better curriculum connections with nature and the environment (Cormell \& Ivey, 2012). As an environmental pedagogy, nature journaling emphasizes experience and reconnection with the more-than-human world, and supports children's holistic, experiential learning in active participation and natural enjoyment (Tsevreni, 2020). Therefore, early years educators and practitioners in 
this new Anthropocene epoch should have the opportunity to use nature journaling to facilitate environmental learning and to deepen relationships with natural world at the micro-and macro-levels. In essence, the central points of Carr and Plevyak (2020) are to urgently call for us to make significant changes in the way we educate children from going beyond connections with nature to focusing on learning for embracing nature as the venue for Environmental Education. This study recommends that educators organize curriculum to foster interdependence in the context of real-world experiences through a nature journaling approach. Beginning with our youngest populace at school, educators should use a nature journaling approach to sustain relationships with nature and enhance children's learning and development in environmental and nature education.

\section{Declarations}

Conflict of interest The author Hongliang Hu states that there is no conflict of interest.

\section{References}

Abshor, U. (2017). The project approach on environmental education: An action research for children's social-emotional development. Asia-Pacific Journal of Research in Early Childhood Education, 11(1), 1-20. https://doi.org/10.17206/apjrece.2017.11.1.1

Alfonso, S. (2016). Implementing the project approach in an inclusive classroom: A teacher's first attempt with project-based learning. Voices of Practitioners, 11(1), 52.

Anderson, D., Chiarotto, L., \& Comay, J. (2017). Natural curiosity 2nd edition: A resource for educators: The importance of indigenous perspectives in children's environmental inquiry. Laboratory School, Dr. Eric Jackman Institute of Child Study, Ontario Institute for Studies in Education, University of Toronto.

Blum, R. (2018). Discovering the outdoors through nature journaling. Nebraskaland Magazine. http:// magazine.outdoornebraska.gov/2018/02/naturejournaling/. Accessed 12 Apr 2018.

Bronfenbrenner, U. (1979). The ecology of human development. Harvard University Press.

Carr, V., \& Plevyak, L. (2020). Early Childhood Environmental Education in the USA. In the book of Elliott, S., Ärlemalm-Hagsér, E., \& Davis, J. (Eds.). (2020). Researching early childhood education for sustainability: Challenging assumptions and orthodoxies. pp.94-108. Routledge.

Chiarotto, L. (2011). Natural curiosity: A resource for teachers: building children's understanding of the world through environmental inquiry. Laboratory School at the Dr. Eric Jackman Institute of Child Study, Ontario Institute for Studies in Education, University of Toronto.

Cormell, J., \& Ivey, T. (2012). Nature journaling: Enhancing students' connections to the environment through writing. Science Scope, 35(5), 38.

Dahlberg, G., Moss, P., \& Pence, A. (2013). Beyond quality in early childhood education and care: Languages of evaluation (3rd ed.). Routledge Taylor \& Francis Group.

Darling, N. (2007). Ecological systems theory: The person in the center of the circles. Research in Human Development, 4(3-4), 203-217.

Elliott, S., \& Davis, J. M. (2018). Challenging taken-for-granted ideas in early childhood education: A critique of Bronfenbrenner's ecological systems theory in the age of post-humanism. In A. Cutter-Mackenzie-Knowles, K. Malone, \& E. Barratt Hacking (Eds.), Research Handbook on Childhoodnature (pp. 1-36). Springer International Publishing. https://doi.org/10.1007/978-3319-51949-4_60-2

Fargas Malet, M., McSherry, D., Larkin, E., \& Robinson, C. (2010). Research with children: methodological issues and innovative techniques. Journal of Early Childhood Research, 8(2), 175-192. https://doi.org/10.1177/1476718X09345412 
Guy-Evans, O. (2020). Bronfenbrenner's ecological systems theory. Study Guides for Psychology Students - Simply Psychology. https://www.simplypsychology.org/Bronfenbrenner.html. Accessed 9 Nov 2020

Johnson, K. (2013). The nature-study movement. Green Teacher, 99, 16.

Johnson, K. (2014). Creative connecting: Early childhood nature journaling sparks wonder and develops ecological literacy. International Journal of Early Childhood Environmental Education, 2(1), 126-139.

Keel, S. (2018). Deepening students' connection to nature. Edutopia, George Lucas Educational Foundation. https://www.edutopia.org/article/deepening-students-connection-nature. Accessed 30 Mar 2018

Laws, J. M., Breunig, E., Lygren, E., \& Lopez, C. (2010). Opening the world through nature journaling. California Native Plant Society. http://sdchildrenandnature.org/attachments/CNPS_Natur eJournalCurriculum_57p_nov10.pdf

Laws, J. M., Breunig, E., Lygren, E., \& Lopez, C. (2012). Opening the world through nature journaling: Integrating art, science \& language arts (Second Edition). California Native Plant Society. http://www.goldrushed.ca/uploads/2/5/7/1/25718175/nature_journalling.pdf

Laws, J. M., \& Lygren, E. (2020). How to teach nature journaling: Wonder, inquiry, attention. Heyday. https://heydaybooks.com/catalog/how-to-teach-nature-journaling-curiosity-wonder-atten tion/

Leslie, C. W. (2001). Teaching nature journaling and observation. Taproot, 13(2), 8-15.

Leslie, C. W. (2002). Teaching nature journaling and observation. Clearing, 111, 15-20.

Leslie, C. W., \& Roth, C. E. (2000). Keeping a nature journal: Discover a whole new way of seeing the world around You. Storey Books, 210 MASS MoCA Way, North Adams, MA 01247.

Lygren, E. (2016). The Laws guide to nature drawing and journaling. Heyday. https://heydaybooks. com/catalog/the-laws-guide-to-nature-drawing-and-journaling/

Muhsin, M. A. (2017). Improving students' writing skills of recount text by applying translationaction-detail (TAD) strategy. IJEE (Indonesian Journal of English Education), 4(2), 156-167.

North American Association Environmental Education (NAAEE) (2019). Nature-based preschool professional practice guidebook: Teaching, environments, safety, administration. Natural Start Alliance and North American Association Environmental Education.

North American Association for Environmental Education (NAAEE). (2000). Early childhood environmental education programs: Guidelines for excellence. https://cdn.naaee.org/sites/default/ files/final_ecee_guidelines_from_chromographics_lo_res.pdf

Ontario Ministry of Education. (2016a). Growing success - The Kindergarten addendum: assessment, evaluation, and reporting in Ontario schools. http://www.edu.gov.on.ca/eng/policyfunding/ growingSuccessAddendum.html

Ontario Ministry of Education. (2016b). The Kindergarten Program. Queen's Printer for Ontario. https://www.ontario.ca/document/kindergarten-program-2016

O’Toole, L., Kiely, J., \& McGillicuddy, D. (2019). Parental involvement, engagement and partnership in their children's education during the primary school years. National Parents Council.

Sobel, D. (1996). Beyond ecophobia: Reclaiming the heart in nature education. https://aura.antioch. edu/facbooks/42

Spinazola, S. A. (2015). Nature walks and journaling to connect children with nature and increase knowledge of the local environment. School of Education Student Capstone Theses and Dissertations. 97. https://digitalcommons.hamline.edu/hse_all/97

Tsevreni, I. (2020). Nature journaling as a holistic pedagogical experience with the more-than-human world. The Journal of Environmental Education, 52(1), 14-24. https://doi.org/10.1080/00958 964.2020.1724854

White, R. (2004). Young children's relationship with nature: Its importance to children's development $\&$ the earth's future. White Hutchinson Leisure \& Learning Group, 1-9. https://doi.org/10.1.1. 494.3009\&rep=rep1\&type $=$ pdf

Publisher's note Springer Nature remains neutral with regard to jurisdictional claims in published maps and institutional affiliations. 
Hongliang $\mathrm{Hu}$ is an early childhood educator (ECE) at a Canadian urban elementary school and also a researcher belonging to the Environmental Education Action Research Team, which is run in partnership through the Ontario Institute for Studies in Education (OISE, University of Toronto) \& the Toronto District School Board (TDSB)'s EcoSchools program. She holds a Master of Education and a Master of Arts; she has her Specialist qualification in Environmental Education. She has been teaching for about 20 years in different diverse educational settings from childcare center and elementary school to university. Her practice is taking learning outside and bringing nature into classroom. She has her research publications related to children's learning and development and her recent research focuses on nature-based and environmental education in the early years. 